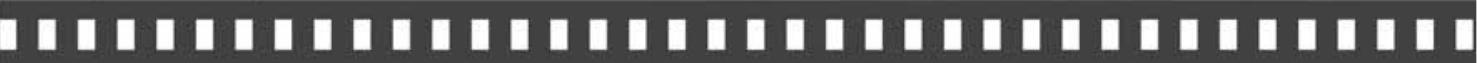

\section{Corpo maculado: a promoção de uma cultura visual do homem na Publicidade}

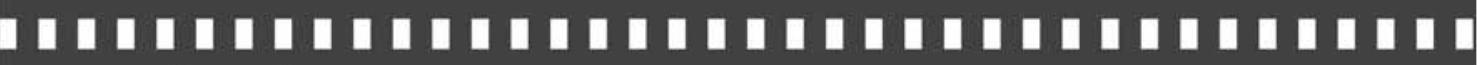

Soraya Barreto Januário

Artigo recebido em: 12/04/2015

Artigo aprovado em: 12/09/2015 


\title{
0 Corpo maculado: a promoção de uma cultura visual do homem na Publicidade *
}

The tainted body: the promotion of visual culture of men in advertising

\author{
Soraya Barreto Januário **
}

\begin{abstract}
Resumo: A pesquisa propõe a análise dos corpos masculinos retratados na publicidade veiculada nas revistas masculinas de estilo de vida. Com o intuito de identificar as características que compõem uma cultura visual baseada na exposição do corpo na publicidade. A abordagem metodológica de investigação será a análise de conteúdo visual nas publicidades veiculadas em 2011 nas revistas de estilo de vida masculinas, nomeadamente Men's Health, GQ Portugal e Max Men.
\end{abstract}

Palavras-chave: Corpo, Masculinidades, Publicidade, Imagem.

\begin{abstract}
The research proposes the analysis of male bodies portrayed in advertising in lifestyle men's magazines. In order to identify the characteristics that make up a visual culture based on body exposure in advertising. The methodological approach of research is the analysis of visual content in advertising aired in 2011 on the lifestyle of men's magazines, including Men's Health, GQ Portugal and Max Men.
\end{abstract}

Keywords: Body, Masculinities, Advertising, Image.

* O artigo traz parte dos resultados de pesquisa doutoral financiada pela Fundação para a Ciência e Tecnologia, Ministério da Educação/ Portugal SFRH / BD / 65186 / 2009.

** Doutora em Comunicação pela Universidade Nova de Lisboa. Publicitária e professora do departamento de Comunicação da Universidade Federal de Pernambuco. Coordenadora do Observatório de Gênero e Comunicação da UFPE. Coordenadora do GT "Gênero e Comunicação" da Rede Feminista Norte e Nordeste de Estudos e Pesquisa sobre a Mulher e Relações Gênero (Redor). 


\section{Introdução}

Novos papéis e perfis vêm sendo definidos para as masculinidades, como fenômeno social que envolve na sua concepção a sociedade de consumo e a indústria cultural através da mídia. Com as mudanças conquistadas pelos movimentos sociais, feministas e econômicos ocorridos nas últimas décadas, ocorreram profundas transformações nas relações de gênero, e por consequência, como seus corpos são representados.

Iniciamos esta discussão questionando o significado de "corpo". O conceito de uma substância material, orgânica ou inorgânica, explicitado no dicionário requer reflexões mais aprofundadas. $\mathrm{O}$ estudo do corpo deve ser analisado numa perspectiva inter/transdisciplinar (SERRES, 2005), já que atravessa campos inegavelmente distintos que vão desde as Ciências Biomédicas às Ciências Sociais e Humanas. A nossa atenção dirige-se para o estudo do corpo e do seu significado social. O que podemos dizer sobre as marcas (LOURO, 2004), as cicatrizes visíveis ou invisíveis e a experiência do ser humano traduzidas no corpo social. Da nossa perspectiva, há nestas experiências uma hierarquia constantes na vida e na morte. As práticas da vida cotidiana são uma ligação que mantêm o individual e o coletivo, visível ou não, na natureza ou na cultura. Ao fomentar um olhar para o corpo através de suas representações na cultura, como é exemplo as fotografias publicitárias, se torna evidente a necessidade de compreender seus significados e discursos no intuito de entender a sociedade a qual pertence. Visamos neste artigo analisar a representação do corpo masculino na Publicidade através o escopo imagético nelas apresentadas. A proposta é identificar a existência ou ausência de uma cultura visual dominante, e também, os elementos que emergem dessas estruturas. Nesse âmbito, dividimos o referencial teórico em duas partes, na qual pretendemos 
compreender como se constrói esse corpo na perspectiva da cultura e como ele surge na Publicidade.

\section{O corpo masculino: uma perspectiva cultural}

O corpo é um lugar que conta histórias, discursa. Para perceber estes discursos é necessário entender o que impede e permite essas enunciações. Sujeito ao regime de dominação masculina que mencionamos, o corpo passa por regularidades que o limitam e que o disciplinam (FOUCAULT, 1979). Segundo Bourdieu (2005) a experiência de viver o corpo é limitada pelo habitus. O autor inspirado pela trabalho de Merleau-Ponty (1994) buscou compreender a centralidade do corpo no conceito de habitus e a relevância que atribui ao corpo-social em suas pesquisas, se relaciona a noção de "esquema corporal". Esse conceito foi usado pelo autor para interpretar posturas corporais e o uso do corpo na vida quotidiana. Bourdieu (2005) argumentou que a relação do corpo com o mundo é ligada à imposição de uma representação legítima do corpo. Sendo um lugar de apropriação de sentido.

Nesse sentido, o autor dialogou sobre a noção de expressão corporal para debater o caráter expressivo do corpo, no qual se comunica ao demonstrar sensações e sentimentos através de uma comunicação gestual. Para Merleau-Ponty (1994) o uso do "corpo expressivo" é uma atitude em relação ao mundo social. E por mais formas de controle social e regulamentação que se encontrem na sociedade, essa expressividade possui um estilo próprio, o caráter individual de cada pessoa em relação a diferentes circunstâncias. Dessa forma, a partir da noção de habitus de Bourdieu (2005) é possível afirmar que mesmo numa sociedade de controle é possível expressar-se corporalmente de formas diferenciadas.

Dessa forma, o corpo social é o corpo de um indivíduo 
portador do habitus, portanto, o corpo seria portador de um sistema de disposições incorporadas que o moldam através de condições materiais e culturais, tornando-o um corpo social. Ou seja, um ser forjado pelas relações sociais num processo de socialização. Passando a orientar práticas corporais que traduzem uma maneira de ser e viver. Essa experiência quotidiana conduz a uma espécie de identidade que representa os limites de existência e dirige o caminho do sujeito. Os corpos são personalizados e domesticados (FOUCAULT, 1999) para a construção individual e coletiva da história sociocultural numa determinada sociedade. Em suma, os corpos são historicamente determinados.

Antropologia concedeu um lugar privilegiado ao tema (TURNER, 1994). No campo da Antropologia Social e Cultural destacaram-se o trabalho pioneiro de Marcel Mauss (2003). Este queria expressar as "maneiras como os homens, sociedade por sociedade e de maneira tradicional, sabem servir-se de seus corpos." (MAUSS, 2003, p. 211). Na sua perspectiva o corpo pode ser um tema de reflexão das Ciências Sociais, além disso, chama a atenção para a questão de como o uso do corpo é aprendido e a sua relação de dependência com os distintos contextos culturais do qual emerge. $\mathrm{O}$ corpo é fruto de uma existência social. $\mathrm{O}$ modo de comportamento como andar, por exemplo, diferem de cultura em cultura.

O conceito de técnicas corporais foi atribuído por Mauss (2003). Através dele o autor afirmava que "o corpo é o primeiro e mais natural instrumento do homem. O mais exatamente, sem falar de instrumento, o primeiro e mais natural objeto técnico, e ao mesmo tempo meio técnico do homem é seu corpo" (MAUSS, 2003, p. 217). A técnica corporal é um modo específico de treinar o corpo imerso numa dada tradição. Isto é, atitudes e formas de agir que parecem ser naturais são na verdade "modos de ser", condicionados pela cultura e pela tradição. É nessa perspectiva que Mauss (2003) falou em tomar o corpo como objeto legítimo de estudo. Norbert Elias (1994) corrobora com Mauss (2003) na intenção de considerar o corpo 
como objeto primordial na Teoria Social. Elias (1994) salientava que o modelo de relações humanas desenvolvido ao longo da modernidade influenciou o domínio das emoções e do inconsciente por intermédio da razão, marcando, os corpos dos indivíduos. Os padrões normativos de comportamento tiveram significativas consequências sobre os corpos.

A 'redescoberta' (BAUDRILLARD, 1991) do corpo e a sua maior visibilidade ocorreram nos anos 60. Após os movimentos sociais de meados desta década, a luta pela quebra de tabus relativos ao corpo, as lutas políticas pela liberdade sexual e o tema corpo ganharam uma releitura em diversas esferas como a política, a mídia, as artes e a ciência. Neste período diversos trabalhos anteriores, como o de Maurice Leenhardt, Lévi-Strauss, estudaram o corpo em diferentes culturas e foram utilizados para os estudos das novas práticas e representações do corpo. Foucault (1999), Turner (1994) e Goffman (1979) tomam o corpo sob a perspectiva da cultura e não como identidade biológica. Ao mesmo tempo entendem que a biologia não se encontra excluída da cultura, antes fazendo parte dela. O dualismo cartesiano foi excluído e os estudos acerca do corpo ganharam forte relevância nas pesquisas sociais, antropológicas e culturais.

Ao pensar o corpo enquanto objeto de análise, Simone de Beauvoir (1980) em Le Deuxième Sexe, confrontou o determinismo biológico e o papel da sociedade e da cultura acerca do gênero. $\mathrm{O}$ lema "nosso corpo nos pertence" é uma das principais bandeiras do feminismo que anseia pela superação do determinismo biológico e da condição feminina. Pierre Bourdieu (1998) tomou o corpo como um dado concreto a ser produzido e reproduzido pela sociedade. Apesar de possuírem concepções distintas e sustentadas em pressupostos diferentes, Beauvoir (1980) e Bourdieu (1998) sustentaram que o corpo é entendido como um processo ativo de incorporação de determinadas possibilidades culturais e históricas. $\mathrm{O}$ corpo é social, pois é moldado pelas normatizações sociais. A 
antropóloga Mary Douglas reconheceu o corpo como um objeto natural moldado pelas forças sociais (DOUGLAS, 2004). Guacira Louro (2004) salienta que "os corpos são significados pela cultura e, continuamente, por ela alterados." (2004, p. 10). A pedagoga chamou a atenção para a existência de "marcas" deixadas no corpo pela cultura, podendo definir identidades deixadas pela cultura.

Butler(2008) referiu-se também às inscrições dos gêneros. A problemática da orquestração de um sujeito "generificado" é também argumentada por Butler (2008), na sua noção de "performatividade" em que masculinidades e feminilidades são construídas através da sedimentação de prática do cotidiano. O gênero é a consequência de uma produção discursiva que se materializa e produz efeitos de realidade através da estilização do corpo (ou da carne). Se o gênero é performativo, o corpo também o é. É através destes atos performativos que o gênero se legitima como representante de uma essência corpórea. O corpo e as suas práticas é que concebem um efeito de realidade e dão ao gênero uma aparente materialidade. O corpo dá assim a ideia de materialidade ou de existência natural às práticas construídas pelo discurso.

Todas estas relações e práticas sociais, além da linguagem, constituem o que se entende por sujeitos femininos e masculinos. E são por isso produtoras das "marcas" (LOURO, 2004) impressas pela cultura. Importa lembrar que essas marcas são efetivadas através de um significativo investimento inscrito nas instituições sociais, tais como a família, escola, Igreja, Estado, entre outras. Estas instituições articulam e reiteram identidades e práticas hegemônicas. Da mesma forma subjugam, subordinam (CONNELL, 2005) ou recusam identidades e práticas não normativas ou conflituosas. A produção dos sujeitos é um processo plural e permanente. É um processo do qual os sujeitos e os seus corpos são participantes ativos na construção das suas identidades. Courtine (2008) destacou que "o corpo foi ligado ao inconsciente, amarrado ao sujeito e inserido nas formas sociais da cultura"(2008, p.8). 
Michel Foucault (1999) encarava o corpo como expressão e sustentáculo das relações de poder e saberes que se articulam na história da sociedade ocidental. O corpo ocupou uma posição central na obra foucaultiana que o ressalta como realidade política, biológica e histórica. $\mathrm{O}$ autor centrou-se nas práticas sociais, nas relações e experiências que o produzem. O corpo é ao mesmo tempo um invólucro e uma superfície que se modela ao longo da história. É matéria física não inerte ou sem vida. Representa sim uma superfície moldável que pode ser alterada, docilizada e transformada por via de técnicas disciplinares, através da biopolítica e do biopoder, teorizados por Foucault desde 'A vontade de saber' (2001), primeiro volume da sua 'História da sexualidade'. "O corpo como máquina: no seu adestramento, na ampliação de suas aptidões, na extorsão de suas forças, no crescimento paralelo de sua utilidade e docilidade, na sua integração em sistemas de controle eficazes e econômicos." (FOUCAULT, 2001, p.51).

O corpo sofre a ação das relações de poder que compõem tecnologias políticas específicas e históricas. É domesticado e disciplinado de acordo com a necessidade da produção capitalista. Para Nobert Elias (1994) as nossas formas de expressões atuais são historicamente justificadas pelos processos sociais e psicológicos desenvolvidos no século XVI. Estas foram originadas pela centralização do poder nas mãos da aristocracia que induzia um certo controle social e emocional e ainda uma maior consciência de si como indivíduo num dado corpo. Este ideal dava a sensação de que a pertença e o sucesso dependiam das boas condutas, da disciplina social e do corpo (ELIAS, 1994). Estes códigos sociais passam a ser um valor cultural que integra o indivíduo num grupo, que ao mesmo tempo tem o poder de o destacar dos outros. Foucault afirma que "foi no biológico, no somático, no corporal que antes de tudo investiu a sociedade capitalista. O corpo é uma realidade biopolítica" (FOUCAULT, 2001, p. 77). Ao longo dos tempos o corpo social consolida-se como algo fabricado, influenciado por uma docilização 
(FOUCAULT, 2001) calculada; esquadrinhado em cada função corpórea, com fins de automatização.

Connell (2005) corroborou com o pensamento de Foucault e argumentou que os corpos tornam-se objetos sobre o qual o homem e a sociedade trabalham através de práticas corporais. $\mathrm{O}$ corpo não consegue escapar da construção da masculinidade; mas tal não significa que o corpo masculino seja fixo. Através das práticas corporais e sociais é moldado ao longo da história, transformando-se em símbolos, significados e posições no discurso. A autora apontou para o fato de na cultura ocidental o gênero masculino ser, entre outras coisas, uma forma de expressão e comprometimento (CONNELL, 2005). Tal funda-se na urgência em abandonar o pensamento social de que a cultura é mutável mas os corpos são fixos. Connell (2005) assinalou que só o abandono dessa idealização permitirá compreender como os corpos masculinos estão envolvidos nas práticas das construções sociais da masculinidade.

Para Le Breton (2006) os corpos são representações das pessoas, uma estrutura simbólica que compreende imagens, sentidos capazes de conjugar uma variedade de culturas. Essa realidade flexível e mutável é estruturada a partir das representações simbólicas, dos imaginários vigentes em determinada sociedade. Le Breton (2006) sugeriu que as técnicas do corpo são compostas por diferentes estilos na sua produção e diferenciam-se de acordo com a faixa etária, etnia, classe social, etc. Ou seja, a construção social do corpo é delimitada pelas diferenças culturais e pelo uso do corpo.

Susan Bordo (2003) corroborou com as afirmações de Le Breton sobre a construção/alteração do corpo quando evidencia que a fantasia de construir um corpo perfeito, belo, magro e jovem é alimentada pelo capitalismo consumista, pela ideologia moderna do interesse por si que se cristaliza na cultura de massa. O consumo parece ultrapassar os limites da prótese, dos adornos e dos acessórios, para envolver uma 'customização' do corpo como matéria alterada, trabalhada. Marzano-Parisoli (2004) ressaltou que 
um conjunto de técnicas sociais operam sobre o corpo para o transformar, moldar. Este é um reflexo de transformações múltiplas, abarcadas pelos valores e crenças da nossa sociedade. Sendo uma imagem cultural passível de sofrer mudança, o corpo tornou-se um objeto a disciplinar, manipular e encenar. Uma imagem domesticada, culturalmente imposta a homens e mulheres.

Um corpo forte e viril vem sendo historicamente concebido no referencial de corporeidade masculina (BEIRAS et. al, 2007), taxados de "normativos" (GLASSNER, 1989). O corpo musculado é indicativo de masculinidade, atestando um ideal de força e virilidade. São os valores que corroboram os arquétipos da masculinidade hegemónica (CONNELL, 1995) ou patriarcal. Tais normas são potenciadas pela mídia e pelas referências publicitárias. Kemp (2005) argumentou que o fenômeno das modificações corporais associadas ao mercado mainstream de beleza estéticas se tem destacado na busca desse corpo, ideal da perfeição, segundo a norma: desde clínicas de estética até aos cirurgiões plásticos.

Cris Wienke (1998) explorou a imagem corporal e o seu significado na vida dos homens. E na tentativa de compreender a relação entre o corpo e masculinidade, desenvolveu investigações utilizando entrevistas em profundidade, analisadas por via de interpretação narrativa. $\mathrm{O}$ autor iniciou a análise considerando a idealização cultural do corpo masculino, concebida no contexto da cultura popular norte-americana. E defendeu que o corpo musculado representa o ideal cultural dominante e aponta aos músculos um caráter central enquanto representantes de masculinidade na cultura popular. Weinke (1998) concluiu que quase todos os sujeitos pesquisados aspiravam possuir um corpo musculado. Garcia (2006) observou que na atual sociedade de consumo abarcada pela mídia o corpo jovem, saudável e robusto passou a funcionar como regra para construir campanhas publicitárias eficientes. Além disso, o corpo musculado passou a ser sinónimo de sucesso e fama. 


\section{Do conceito de imagem à imagem publicitária}

A imagem pode ser entendida enquanto reprodução, símbolo, metáfora e/ou representação. A palavra imagem, apesar de abranger muitos territórios, pode ser referida tanto a propósito de uma banda desenhada (BAIRD, 2010) como de uma representação pictórica de paisagem ou objeto. Isto é, está presente desde as imagens lúdicas até as mais rebuscadas e complexas formas de representação. A imagem assume uma pluralidade de significados, multiplica-se numa utilização abrangente em diferentes contextos, é facilmente utilizada no discurso cotidiano e de senso comum, em dialeto popular "a imagem da perfeição". Já no âmbito acadêmico, o conceito de imagem deve ser empregue com cautela conceitual, além do que a sua definição vai depender do campo de estudo em causa (PINK, 2001; CAMPOS, 2007). Nessa perspectiva, é necessário realizar uma desconstrução do conceito devido a sua densa carga de significados simbólicos. E que tem imposto ao poder religioso, político e social, certo cuidado no seu emprego, principalmente na esfera pública.

Segundo Joly (2005) "compreendemos que [a imagem] indica algo que, embora nem sempre remete ao visível, toma alguns traços emprestados do visual e, de qualquer modo, depende da produção de um sujeito: imaginária ou concreta, a imagem passa por alguém que a produz ou reconhece" (JOLY, 2005, p.13). O interesse que a imagem possui enquanto objeto de estudo desperta, de alguma forma, a ciência para a uma necessidade de "domesticação" (FOUCAULT, 1990), dado o poder representativo, subjetivo e manipulável que a imagem possui. Essa domesticação consiste em explorar seus significantes, conhecê-los, disseca-los para uma contenção mais cuidada e consciente na 'produção' de tais mensagens construídas na imagem. 
Na prática é a representação de algo por semelhança. Joly (2001) afirmou que a analogia é o ponto comum entre as diferentes significações da imagem. Segundo a autora, uma imagem é, antes de mais, algo que se assemelha a alguma coisa. Este entendimento aplica-se até mesmo quando a imagem é abstrata, como nos sonhos, quando, por exemplo, a imagem se parece com a visão natural dos objetos e coisas. Joly (2001) ressaltou que a imagem não se caracteriza apenas por ser um signo icônico ou figurativo: ela pode cruzar-se com diferentes e diversos materiais que a compõem para constituir uma mensagem visual. Nesse sentido, a mensagem visual pode ser construída com signos icônicos que dão a impressão de semelhança com a realidade.

Clifford Geertz (1989) afirmou que a cultura é pensada como sistema simbólico, possível devido ao isolamento histórico de grupos de indivíduos, expressa as relações próprias da comunidade passando por gerações até caracterizarem-se por um sistema integrado de ações conjuntas, identificadas por sua ideologia, crenças, expressões e formas de ser e estar. Segundo Geertz (1989) todas as correntes teóricas que buscaram compreender o homem no conjunto de seus costumes adotaram uma tática de relacionar os fatores biológicos, psicológicos, sociais e culturais entre si, denominada por ele como "concepção estratigráfica." A estratigrafia tem a intenção de perceber o homem como a sobreposição destes fatores em camadas completas e irredutíveis. Os fatores culturais, neste conceito de estratificação hierárquica, não se misturam com os demais fatores, pressupondo uma relação de independência.

Para Bourdieu (1989) a construção coletiva é influenciada pela representação explícita e da expressão verbal. Na obra Les héritiers, Bourdie e Passaron (1964) desenvolveram o conceito de "capital simbólico" na qual a noção do conceito não se dissocia dos efeitos da dominação. Isto porque o "espaço social" para Bourdieu (1989) é um espaço de lutas, por isso a importância das estruturas simbólicas (como a cultura) como exercício da legitimação de um grupo sobre 
os outros. Para o autor "capital simbólico" é a segunda mais importante expressão do capital, à qual precede apenas o capital econômico portado pelos agentes sociais e quase tão poderoso quanto ele.

Bourdieu (1989) ressaltou que os sistemas simbólicos dominantes ou considerados legítimos numa dada sociedade são aqueles construídos e operados pelos grupos que conseguiram se colocar em posição dominante. A cultura torna-se, então, dominante porque é a cultura dos grupos dominantes, e não porque carrega em si algum elemento que a torne superior (ALMEIDA, 2007, p. 47). Bourdieu e Passaron (1964) criticaram o pensamento social vigente na qual acreditava-se que o "gosto" era uma questão ligada ao foro íntimo. O autor argumentou que o "gosto" seria o resultado de relações de força poderosamente alicerçadas nas instituições transmissoras de cultura da sociedade capitalista. $\mathrm{Na}$ qual, essas instituições seriam a família e a escola, responsáveis pelas nossas competências culturais ou gostos culturais. Por um lado, descreveu o aprendizado precoce efetuado desde a primeira infância, transmitido pela família, e prolongado pela educação escolar que o pressupõe e o complementa. Por outro lado, destaca os aprendizados tardios e metódicos, adquiridos nas instituições de ensino, fora do ambiente familiar. Essas duas formas de aprendizado, segundo Bourdieu (1989), seriam responsáveis pela formação do gosto cultural dos indivíduos e constitui o "capital cultural incorporado".

O termo cultura empregue como sinônimo de civilização, através da tradição iluminista, é interpretado por agentes sociais e/ou históricos; é uma ideia de civilização, representada por um coletivo que define certas normas. O ser humano, inserido numa teia de significados, procura na sua formação cultural características múltiplas de relacionamento no pensar e agir (GEERTZ, 1989; ELIAS, 1994). Geertz afirmou que se baseou na leitura conceitual de Max Weber e afirmava ser o homem um animal amarrado as teias de significados que ele mesmo teceu. Nessa perspectiva, devido ao foco 
da nossa pesquisa estar associado as questões da visualidade, propomo-nos a compreender tais teias e significados que se ligam as questões da imagem e do visual, sendo pertinente a análise da Cultura Visual.

Apesar da noção de visual constituir uma dimensão diferente da linguagem verbal, isso não implica que a Cultura Visual considere apenas o aspecto visual. Mas, sobretudo, a Cultura Visual inclui a relação com todos os outros sentidos e linguagens. Malcolm (2001) Barnard, na obra Approaches to understanding visual culture, identificou duas correntes fundamentais nos estudos da Cultura Visual. A primeira enfatiza o visual e trata de formatar e prescrever os seus objetos de estudo como sendo a arte, o design, as expressões faciais, a moda, a tatuagem, etc. A segunda corrente toma a cultura como traço definidor do estudo, e portanto refere-se a valores e identidades construídos e comunicados por aquela através de uma mediação visual, como também enfatiza a natureza conflituosa desse visual devido aos seus mecanismos de inclusão e exclusão de processos identitários.

Defensor da segunda corrente, Mirzoeff (2002) acreditava que a visualização é uma das características do mundo contemporâneo. Contudo isso não significa que se conheça necessariamente aquilo que se observa. Para o autor, a experiência visual na cultura contemporânea e a habilidade para analisar esta observação vem ao encontro da necessidade de converter a Cultura Visual num campo de estudo. Para Mirzoeff (1999), a disciplina está associada à tendência moderna para visualizar a existência, uma competência relativamente recente na história da humanidade e que traduz a centralidade do olhar e da visualidade no entendimento e representação do real (MEDEIROS, 2011). Mirzoeff (1999), principal defensor desta corrente, afirmou que: 
não se trata de uma história das imagens, nem depende das imagens em si mesmas, mas sim dessa tendência de plasmar a vida em imagens ou visualizar a existência, pois o visual é um lugar sempre desafiante de interação social e definição em termos de classe, gênero, identidade sexual e racial (MIRZOEFF,1999, p. 52).

Nesse sentido, a Cultura Visual, pode ser compreendida, como um conjunto de composições visuais, associado a contextos particulares ou coletivos, onde a linguagem e signos visuais são elaborados, relacionados e trocados entre o seu coletivo. Esse conjunto corrobora com a apreensão de conhecimento e a sua descodificação permite entender visualmente a realidade e o aglomerado social, político e cultural de determinadas sociedades. Esta técnica é de grande importância para a compreensão da teia de significados (GEERTZ, 1989) que compõem as representações visuais na mídia, e especialmente na Publicidade. A imagem publicitária caracteriza-se por sua intencionalidade, destina-se a um público pré-determinado através de mecanismos de produção de sentido. É essa imagem que desperta sentidos e cativa emoções, modela a imaginação e mitifica pessoas, objetos e serviços. Como linguagem icônica é resultado de uma estratégia significativa e como tal persuasiva. A imagem impacta diretamente o sentimento. E por esse motivo, é tão importante analisar os apelos visuais no objeto publicitário. Dessa forma, torna-se inerente aos objetivos dessa investigação compreender os simbolismos e personagens que emergem do argumento publicitário.

Para Santos (2005), o fenômeno da publicidade "é composto de partes interrelacionadas e interdependentes (o sistema), que interagem entre si e com o ambiente. Isso quer dizer que a publicidade está inserida num sistema social, do qual sofre interferências e sobre o qual interfere" (2005, p. 19). O autor afirmou que é possível observar na publicidade atual três elementos que a identificam: a capacidade de informação, de dar a conhecer o produto e seus possíveis ideais; a força persuasiva, a sua capacidade 
de convencer, de dialogar com o público e o levar a uma ação e o último, o caráter comercial, o objetivo final da publicidade, o de levar o seu público a tomar uma decisão de compra, seja de um serviço ou produto, assumindo assim um caráter comercial (SANTOS, 2005).

\section{O que surge da imagem masculina na Publicidade?}

Desde as nossas indagações iniciais explicitámos o interesse em entender quem são os personagens que surgem nas revistas e quais as suas características implícitas no modo como são retratados e representados na mídia. Eis a razão para o nosso primeiro olhar ter recaído sobre os personagens que surgem nos anúncios publicitários.

A metodologia empregue para análise das propagandas veiculadas no ano de 2011 na Men's Health, GQ Portugal e Max Men foi a análise de conteúdo. A nossa escolha centrou-se em revistas de estilo de vida, dirigidas ao público masculino, com implementação e credibilidade no mercado editorial de Portugal e que representassem linhas temáticas pertinentes para os estudos de gênero e masculinidades, tais como: comportamento masculino, relacionamentos, corpo e sexualidade. Dessa forma, a amostra da pesquisa conta com 257 peças publicitárias distintas. Para Bardin (1979) a análise de conteúdo consiste em: “ [...] um conjunto de técnicas de análise de comunicação visando a obter, por procedimentos sistemáticos e objetivos de descrição do conteúdo das mensagens, indicadores (quantitativos ou qualitativos) que permitam a inferência de conhecimentos relativos às condições de produção/recepção dessas mensagens" (BARDIN, 1979, p.42). Com o intuito de uma nova leitura do material imagético e textual visa revelar o que está escondido ou subentendido na mensagem. "A análise de conteúdo procura conhecer aquilo que está por trás das 
palavras sobre as quais se debruça. [...] é uma busca de outras realidades através das mensagens" (BARDIN, 1979, p.44). Em relação a este tópico, e tal como era esperado, verificou-se a predominância de personagens masculinos, configurando 77\% dos 282 personagens que perfazem a amostra no universo dos 257 anúncios analisados.

O desejo e a aspiração a certos ideais de beleza reforçados pelos meios de comunicação (MOTA-RIBEIRO, 2005; VERÍSSIMO, 2008; WOLF, 2009) têm influenciado novas formas de perceber a masculinidade e a representação masculina na mídia (NIXON, 1996), tanto mais se considerarmos que os ideais de beleza são prerrogativas humanas e não apenas femininas, como se defendia. Eco (1985) advogou que a modernidade afetou o mundo e a forma de viver a masculinidade. Nesse sentido, constata-se que $89 \%$ dos homens e $92 \%$ das mulheres retratados na publicidade destas revistas correspondem a padrões socialmente idealizados de beleza. Mota-Ribeiro (2005) argumentou que "A noção de beleza não é simples e presta-se a considerações de caráter cultural.” (2005, p. 114). Assim, é possível afirmar que as imagens de homens e mulheres nestes anúncios são manifestações evidentes de ideais e padrões de beleza socialmente construídos, com o intuito de fomentar disciplina (FOUCAULT, 1999).

Além da beleza em geral, destacam-se outros dois pontos, associados ao "ideal de aspiração" que as pessoas perseguem: por um lado a magreza das mulheres (Figura 1) e o corpo musculado dos homens por outro (Figura 2). De acordo com tais arquétipos canonizados de beleza "[...] a mulher ideal está frequentemente associado à beleza do rosto ou à pureza de suas formas anatómicas [...] No homem é valorizado o aspecto físico, sendo o peito e os ombros largos as partes mais destacadas e que representam a metáfora do triunfo profissional e sucesso pessoal [...]" (VERÍSSIMO, 2008, p. 168).

Lipovetsky (1989) fundamentou estes padrões no fenômeno de 
investimento no culto do corpo. Naomi Wolf(2009), no seu afamado The beauty mith, argumentou que a beleza enquanto valor normativo foi construída socialmente. Para a autora tal construção decorre de valores patriarcais, cujos seus conteúdos, tanto discursivos como imagéticos, tinham o intuito de reproduzir a sua própria hegemonia. A autora salientou ainda que o culto da magreza feminina não se justifica apenas em nome da beleza da mulher, da questão estética; mas sim na sua obediência - sendo a dieta "o sedativo político" mais potente da história da mulher (2009, p.51-62). O excessivo investimento no aspecto físico, fomentado pelos diferentes meios de comunicação social e por alguns setores sociais, tem por objetivo a dominação, aprisionando a mulher aos limites do seu corpo.

Por outro lado, este processo de disciplinar do corpo (FOUCAULT, 1979) não escraviza apenas as mulheres; o corpo masculino também tem desempenhado um grande esforço para responder ao ideal de homem fundado na imagem de um corpo musculoso, na sua performance social e sexual, e na velha discussão sobre a representação do tamanho do pênis (POPE et. al., 2000). Sob esta ótica, os autores em questão afirmaram que os homens têm sacrificado aspectos importantes das suas vidas na busca do corpo perfeito. Bourdieu (2005), ao discutir o corpo, afirmou que os homens tendem a mostrar-se insatisfeitos com as partes que consideram "pequenas" na respetiva compleição física. Enquanto isso, nas prerrogativas universalizantes do feminino, as críticas em relação ao seu corpo são dirigidas para as áreas que lhe parecem grandes demais. Assim como Wolf (2009), o autor acreditava que o processo de dominação masculina - ou o patriarcado, como era designado por Wolf (2009) - tem o poder de colocar as mulheres e homens num permanente estado de insegurança em relação ao aspecto físico. Segundo Wolf (2009), ao viver num estado de dependência simbólica, as mulheres existem através do olhar dos outros como objetos receptivos, disponíveis. Nesse contexto ser magra contribui para a ideia social do que é ser mulher; por seu lado 
ser forte vai ao encontro do que é másculo, do que é ser homem. Nesse sentido, o homem também experiencia processo idêntico da sua própria relação de dominação (BOURDIEU, 2005), daí resultar a busca de um corpo musculado, forte assim como a potência e a virilidade. E fomenta a própria discussão de modelos não hegemônicos de masculinidades como é explicitado por Connell (2005).

Outro aspecto a ponderar ao nível das variáveis encontradas é o da juventude, um eixo que nos chamou atenção ao cruzarmos os dados de gênero e de faixa etária. Segundo Mota-Ribeiro que abordou a dimensão feminina na publicidade " afirma-se o ideal da juventude como contributo para a noção de beleza" (2005, p. 111). Não estamos tratando aqui o conceito de "juventude" proposto por Edgar Morin como uma "classe de idade" (MORIN, 2006), aqui é empregue a ideia alimentada pela visualidade publicitária da mulher entre os 20 e 30 anos (MOTA-RIBEIRO, 2005). Desta forma constatou-se uma tendência para o recurso a homens jovens (25-35 anos) em cerca de $61 \%$ das representações; enquanto isso, as mulheres tiveram maior representatividade na mesma faixa etária. A este aspecto acresce ainda uma forte propensão para o recurso a mulheres ainda mais jovens (18-24 anos), na casa dos 32\%. Estes elementos sugerem fortemente o papel de chamariz que as mulheres jovens desempenham nestas peças publicitárias.

\section{Os corpos representados}

Além de saber como os personagens são apresentados fisicamente, importa averiguar também de que modo os seus corpos são retratados e como se comportam nessas representações, tudo isto tendo em conta os ideais de beleza específicos aqui promovidos. Sobre a aparição do corpo nesses anúncios identificamos alguns elementos que, inicialmente nos impressionaram: 
Cerca de 90\% dos homens e $84 \%$ das mulheres estavam vestidos. Apesar do recorrente emprego de mulheres seminuas no conteúdo editorial das revistas, o mesmo não se repete nos anúncios. Os homens mantêm uma certa "imagem imaculada" do corpo. Isto indicia algum cuidado com a exposição do corpo masculino. Segundo Veríssimo (2008) esse tipo de resultado "demonstra-nos que a nudez continua a ser um tabu, e mesmo na publicidade destinada a promover produtos de tratamento corporal, este recurso é limitado" (2008, p.174).

Nota-se que as mulheres tendem a aparecer mais despidas do que os homens, inclusivamente em ambientes em que não faz nenhum sentido (Figura 3). Na peça publicitária da marca Hugo Boss dois homens bem vestidos parecem ostentar o "troféu" que representa a mulher seminua, de saltos, numa clara objetivação do corpo feminino (MOTA-RIBEIRO, 2005, VERÍSSIMO, 2008). Homens brancos, jovens, (aparentemente) ricos que possuem uma mulher bonita, condizente com os padrões de beleza vigentes, personificando um mero "enfeite" - do nosso ponto de vista constitui uma clara representação de poder e dominação masculina.

As poucas ocorrências em que surgiram mulheres e homens nus ou seminus estão relacionadas essencialmente com as áreas da moda, perfumaria e tratamentos estéticos. Essas representações fomentam uma cultura visual do masculino associado à virilidade, acentuando o homem musculado e forte, como já se constatou anteriormente na Figura 3. No âmbito da moda, os anúncios que surgiram eram sobretudo de roupas íntimas masculinas que, devido ao produto, justificam a representação de um corpo despido, com os anúncios de roupa interior masculina (Figura 4), envolvendo uma forte representação do corpo trabalhado, musculoso e com ênfase no plano americano (mostra o personagem da cintura ou joelhos para cima) que dá ênfase ao corpo e não ao rosto ou a identidade da pessoa.

Pudemos identificar que as características mais recorrentes 
que emergiram das encenações configuram um homem jovem, que se integra nos ideais de beleza e estéticas vigentes, de etnia caucasiana, que veicula uma atitude relacionada com a ação, a produção. Refira-se que a maioria dos personagens aparece vestida. Este homem parece encaixar exatamente nas descrições sobre as masculinidades hegemônicas, elencadas por Connell (2005). Este é o retrato dominante do homem representado na maioria dos anúncios do universo da amostra selecionada. Nesta perspetiva, podemos afirmar que o nosso corpus representa uma cultura visual promotora de uma hegemonia de etnias, de ideais de beleza, juventude, e claro, de gênero.

\section{Considerações Finais}

Dentre as imagens publicitárias analisadas foi possível notar que em sua maioria a representação de uma beleza idealizada se torna evidente (WOLF, 2009). Algumas delas colocam em destaque o corpo, privilegiando a parte superior do tronco, nu e rigidamente musculado, tudo isto numa clara observância dos ditames da indústria cosmética e do consumo (CASTRO, 2007). Dessa forma, notou-se claramente o predomínio dos padrões de beleza veiculados por homens jovens e preocupados em cultivar a sua própria imagem. Isto permite-nos concluir que estes "novos" modos de se ser homem vêm associados a um tom de persuasão e de controle. Aliado à tentativa de um discurso sedutor soma-se um processo de agendamento identitário, que visa a disciplina dos sujeitos, a sua sujeição (FOUCAULT, 2006). Foram vários os exemplos detectados, tanto na análise de conteúdo como na promoção de uma cultura visual.

Um dos aspectos a ressaltar nestes casos é a preocupação com a própria imagem, com a sua autorrepresentação e estética. Esta nova preocupação no masculino, segundo Mira (2003), “derivaria de uma 
mudança de orientação da ética do trabalho para a do prazer entre os homens jovens das classes altas, teria a ver com a expansão do mundo da arte nas grandes metrópoles ou com a ampliação das possibilidades de estetização da vida cotidiana" (2003, p. 36). É preciso lembrar também a dimensão do poder associado à beleza e à estética e que ganhou força na contemporaneidade. $\mathrm{O}$ corpo masculino continua sendo um espaço de demonstração de poder, e a beleza se tornou uma nova forma de associar essa nova forma de perceber as relações de poder social relacionada aos gêneros.

\section{Referências Bibliográficas}

BAIRD, Michael J. Falangs in T.hailand: Adult Cartoon.

E-Book: Booksmango, 2010.

BARDIN, Laurence. Análise de conteúdo. Lisboa: Edições 70, 1979.

BARNARD, Malcom. Approaches to understanding visual culture. Nova Iorque: Palgrave, 2001.

BAUDRILLARD, Jean. Simulacros e Simulação. Lisboa: Relógio d'Água, 1991.

BEAUVOIR, Simone. (1980). O segundo sexo. Rio de Janeiro: Nova Fronteira.

BEIRAS, Adriano, LODETTI, Alex, CABRAL, Arthur., TONELI, Maria Juracy., BORDO, Susan. Unbearable weight: Feminism, Western culture, and the body: University of California Press, 2003. 
BOURDIEU, Pierre. Conferência do prêmio Goffman: a dominação masculina revisitada. En: Daniel, Lins (Ed.), A dominação masculina revisitada (pp. 11-27): Campinas: Papirus Editora, 1998.

BOURDIEU, Pierre. A dominação masculina. Rio de janeiro: Bertrand Brasil, 2005.

BOURDIEU, Pierre.; PASSERON, Jean Claude. Les héritiers: les étudiants et la culture. Paris: Les Éditions de Minuit, 1964.

BUTLER, Judith. Problemas de gênero: feminismo e subversão da identidade. Rio de Janeiro: Civilização Brasileira, 2008.

CAMPOS, Ricardo. Pintado a cidade. Uma abordagem antropológica ao graffiti urbano. Tese de Doutoramento, Universidade Aberta, Lisboa, 2007.

CASTRO, Ana Lúcia. Culto ao corpo e sociedade: mídia, estilos de vida e cultura de consumo (Vol. 234). São Paulo: Annablume, 2004.

CHARAUDEAU, Patrick. Discurso das mídias. São Paulo: Contexto, 2007.

CONNELL, Raewyn. Masculinities. California: University of California Press, 2005.

COURTINE, Jean Jacques. O corpo inumano. In Alain Corbin, Jean Jacques Courtine e Georges Vigarello (Eds.), História do corpo (pp. 487-502). Petrópolis: Vozes, 2008. 
DOUGLAS, Mary. $\mathrm{O}$ mundo dos bens: para uma antropologia do consumo. Rio de Janeiro: UFRJ, 2004.

ELIAS, Nobert. A sociedade dos indivíduos. Rio de Janeiro: Jorge Zahar Editora, 1994.

FOUCAULT, Michel. Microfísica do poder. Rio de Janeiro: Edições Graal, 1979.

FOUCAULT, Michel. Vigiar e Punir: nascimento da prisão. Petrópolis, Rio de Janeiro: Vozes, 1999.

FOUCAULT, Michel. História da sexualidade I: a vontade de saber. Rio de Janeiro: Graal, 2001.

GARCIA, Sandra. Homens na Intimidade: masculinidades contemporâneas: Holos Editora, 2006.

GEERTZ, Clifford. As interpretações das culturas. Rio de Janeiro: Guanabara, 1989.

GLASSNER, Barry. Men and muscles. In Michael. S. Kimmel; Michael. A. Messner (Eds.), Men's Lives (pp. 252-261). Boston: Allyn and Bacon,1989.

GOFFMAN, Erving. Gender advertisements. Cambridge: Harvard University Press, 1970.

LIPOVETSKY, Gilles. A era do vazio. Lisboa: Relógio d'água, 1989.

LE BRETON, David. A sociologia do corpo. Petrópolis: Vozes, 2006. 
LE BRETON, David. Adeus ao Corpo. Antropologia e Sociedade. São Paulo: Papirus., 2009.

LOURO, Guacira Lopes. O Corpo educado: pedagogias da sexualidade. Belo Horizonte: Autêntica, 2000.

LOURO, Guacira Lopes. (2004). Um corpo estranho: ensaios sobre sexualidade e teoria queer. Belo Horizonte: Autêntica, 2004.

MARZANO-PARISOLI, Maria Micaela. Pensar o corpo.

Petrópolis: Vozes, 2004.

MAUSS, Marcel. Sociologia e Antropologia. São Paulo: Cosac Naify, 2003.

MEDEIROS, Margarida. Fotografia e verdade. Uma história de fantasmas. Lisboa: Assírio e Alvim, 2011.

MIRA, Maria Celeste. O masculino e o feminino nas narrativas da cultura de massas ou o deslocamento do olhar. Cadernos Pagu, 21, 13-38, 2003.

MIRZOEFF, Nicolas. An Introduction to Visual Culture.

Londres e Nova Iorque: Routledge, 1999.

MIRZOEFF, Nicholas. The visual culture reader. Londres e Nova Iorque: Routledge, 2002.

MOTA-RIBEIRO, Silvana. Retratos de mulher: construções sociais e representações visuais do feminino. Porto: Campo das letras, 2005. 
NIXON, Sean. Hard looks: Masculinities, spectatorship and contemporary consumption. Londres: UCL Press, 1996.

SANTOS, Gilmar. Princípios da publicidade. Belo Horizonte: Editora UFMG, 2005.

SERRES, Michel. O Incandescente. Rio de Janeiro: Bertrand Brasil, 2005.

TURNER, Terence. Bodies and antibodies: flesh and fetish in contemporary social theory. In T. Csordas (Ed.), Embodiment and experience: the existencial ground of culture and self ( $\mathrm{pp}$. 27-47). Cambridge: Cambridge University Press, 1994.

JOLY, Martine. A Imagem e os signos. Lisboa: Edições 70, 2005.

PINK, Sarah. Doing ethnography: Images, media and representation in research. Londres: Sage, 2001.

POPE, Harrison; PHILLIPS, Katharine; OLIVARDIA, Roberto. The Adonis complex: The secret crisis of male body obsession. Sydney: The Free Press, 2000.

VERÍSSIMO, Jorge. O corpo na publicidade. Lisboa: Colibri, 2008.

WIENKE, Cris. Negotiating the male body: Men, masculinity, and cultural ideals. The Journal of Men's Studies, 3(6), 255-282, 2008.

WOLF, Naomi. The beauty myth. Nova Iorque: Harper Collins, 2009. 